\title{
WORKFLOW FOR AN EVIDENCE-BASED VIRTUAL RECONSTRUCTION: THE MARBLES OF THE CIBORIUM OF THE EARLY MEDIEVAL MONTE SORBO CHURCH
}

\author{
E. C. Giovannini ${ }^{1}$ \\ ${ }^{1}$ DAD - Dept. of Architecture and Design, Politecnico di Torino, Italy - elisabettacaterina.giovannini@polito.it
}

Commission II, WG II/8

KEY WORDS: 3D modelling, photogrammetry, cultural heritage, digital reconstruction, pergola and ciborium, marbles

\begin{abstract}
:
The paper presents a practical approach to define a hypothetical virtual reconstruction of the ciborium and pergola of Monte Sorbo's Church. The high accuracy of archaeological fragments, digitally acquired, allowed to hypothesize the entire sequences of decorations of architectural elements and to define their geometrical rules. Starting from the acquisition to the $3 \mathrm{~d}$ modelling phase, the proposed virtual reconstruction combines original fragments with their lost parts modelled in a digital environment.

Digital technologies offer nowadays the great possibility to visualize and understand cultural heritage in a new and attractive way. Digital models and virtual reconstructions have a key role in encouraging and promoting the development of good practices for recording, documenting, and making accessible scientific processes beyond visual appearance. The term virtual reconstruction, within the project, is used to describe a procedure that consists of making a 3D model that reproduces a digital copy of the original, assembling digitally acquired fragments with elements philologically reconstructed following the evidence-based geometrical rules. This study aims to contribute to this growing area of research by exploring possibilities on digital integration of different $3 \mathrm{~d}$ models to re-define a visual appearance of lost architectural elements.
\end{abstract}

\section{INTRODUCTION}

$3 \mathrm{D}$ virtual reconstructions of no longer existing heritage is a commonly used practice to communicate cultural heritage. This research takes up the challenge of creating a system to document the phases of virtual reconstruction using $3 \mathrm{D}$ web visualisation.

Since 1990's digital techniques were applied to create Virtual Archaeology (Reilly, 1991) and new virtual environments were developed to recreate the visual appearance of large buildings (Dell'Unto et al., 2013), city models (Guidi et al., 2007) and architectural landscapes (Von Schwerin et al., 2013).

It is commonly recognised by the scientific community that a reconstruction process involves a diverse type of sources and how their explicit or implicit derived knowledge is relevant in the 3D modelling phase (Apollonio et al., 2013; Borghini and Carlani, 2011; Hermon, 2008; Remondino et al., 2009) considering a cross-disciplinary approach (Friedrichs, 2018; Münster et al., 2018). How to document and visualise the virtual reconstruction processes is a topic with an ongoing debate that comprise themes of uncertainty and the possibility to have alternative options for three-dimensional reconstruction. Starting from the London Charter for the Computer-based Visualisation of Cultural Heritage (2006) to the Seville Principles for Virtual Archaeology (2011), the topic of transparency in virtual heritage (Denard, 2012) reflects the importance of being honest in the communication of digital cultural heritage. Both documents suggest guidelines to avoid weaknesses and inconsistencies related to the use of computer-based visualisation introducing the necessity to document processes using metadata and paradata (Apollonio and Giovannini, 2015). Others authors focus their research to establish criteria to make the reconstructive process understandable (Apollonio, 2016; de Kramer, 2020; Demetrescu et al., 2016) and objectively quantifiable (Niccolucci and Hermon, 2010). Regarding the reconstruction processes, documentary heritage and historic images are usually the only sources used to model no more extant objects (Münster, 2013). In the case of ciborium and pergola of Monte Sorbo's church, the presence of fragments allows determining the measures of the arcades of the ciborium, slabs and other elements belonging to the pergola. The geometrical analysis of decorative elements allowed to hypothesize a possible repositioning of fragments with a high degree of reliability thanks to the use of digital technology. The process of virtual repositioning of fragments in their original location is sometimes also defined as virtual anastylosis and can be carried on using automatic matching among scattered and fragmented elements (Canciani et al., 2014; Thuswaldner et al., 2009). Other approaches to the recomposition of the original artefact follow geometrical rules to define the position of fragments (Abate et al., 2011; Adembri et al., 2017).

More recently, in the light of emerging Semantic Web technologies, new studies focused on the possibility to use webbased research environment to manage digital 3D reconstructions (Kuroczynski, 2017) considering documentation standards for Linked Data requirements (Mi and Pollock, 2018; Moraitou et al., 2019).

Technological developments during the last years involved both tools for 3D modelling, both tools for visualisation and communication of digital models. These tools play a key role to reach a new digital audience and to present research in a novel and attractive way.

The digital revolution in the field of Cultural Heritage allow to access to digital archives, digital libraries, 3D archives and organized repositories such as CyArk, Europeana and Open Heritage 3D. Despite growing of initiatives related to the 3D web publishing, a common methodology to visualise 3D models with research sources, visualising implicit knowledge and derived multidisciplinary explicit assumptions have not yet been defined. The principal issue is related to the necessity to communicate scientific content to non-experts audience. Interdisciplinary research is nowadays carried on by diverse figures with a different background that produces a heterogeneous dataset. The web publishing of this kind of content is an ongoing challenge that involves the documentation format and the concurrent visualization of 3D models with different level of detail (Boutsi et 
al., 2019). The commonly used interfaces used to publish 3d content were OpenGL, Direct 3D and Java 3D but nowadays thanks to the advent of WebGL new framework are available such as SketchFab and Unity 3D that requires low-level programming. Finally, a reference example of academic platforms developed to integrate 3D content in a web page using HTML are X3DOM (Behr et al., 2009) and 3DHOP (Potenziani et al., 2018, 2015), while Potree (Martinez-rubi et al., 2015) is dedicated to the visualisation of large point clouds in Web browsers.

In this research, the use of $3 \mathrm{DHOP}$ allowed to fully manage the visualisation of different developed 3D models using the same 3D scene. Model instances inside 3DHOP were configured to be visible and invisible thanks to the use of a specific tag that was associated with each model instance. The tag property, that is a series of strings, allowed to manage the complexity of the virtual reconstruction process layering different type of 3D information associated with different tags: from the raw data to the visualisation of $3 \mathrm{D}$ integrations.

The aim was to provide new visual support to increase the perception of the ancient artefact by recreating it as it should have appeared in its initial configuration.

\subsection{The Early Medieval Monte Sorbo's Church}

Monte Sorbo church (Sarsina, central Italy) is an ancient, rural church, with a Romanic architectural appearance, located in the Emilia-Romagna region, between the valleys of Savio and Borello rivers.

The origin of the church is still subject to debate but some historical data suggest that the church already exists in $948 \mathrm{AD}$ (Abati and Camporesi, 2014). Mengozzi provides a hypothetical sequence for the evolution of the church over the centuries but unfortunately is not supported by enough historical documentation (Mengozzi, 2014). The tradition of local studies assumes that today's church is built on the stratification of different planimetric installations starting from an earlier Roman temple or an Early Christian Church (VI-VII) that was already made reusing marbles such as columns and capitals, nowadays in the central nave, and that do not originate from the local Apennine geological formations and are thought to come from extra-regional sources.

The presence of a huge number of spolia, fragments, columns and capitals of diverse provenance and that belongs to different historical periods, suggests that probably the church changes many times over centuries. The most significant marbles can be dated to centuries VIII-IX (Porta, 2014) and they consist of a series of fragments scattered in several places and sometimes of considerable size: plutei with a cross, slabs, tombstones, capitals, columns, and newels. The presence of marble architectural fragments conserved inside the church presupposes a monumental sculptural complex consisting of a ciborium and pergola.

The pergola is a typical Early Christian and Early Medieval liturgical installation, with the function of separating the choir and presbytery, where the clerics and the celebrant stood, from the nave, occupied by the faithful.

The presence of the ciborium is a great example of reuse of marbles during the Early Medieval Period: a recent study confirms that artefacts belonging to the ciborium were made by Proconnesian marble from the island of Marmara and that material was used extensively from the Archaic age to ByzantineOttoman period (Antonelli et al., 2016). Nowadays the S. Maria Annunziata of Monte Sorbo church is composed of three naves with a planimetry that correspond to a pseudo-latin cross. The semi-circular apse was probably built between centuries XIIXIII. The current ciborium is dated in 1442 and is supported by marbles columns with capitals that probably belongs to the ancient one.
The Church was completely restored over the past years and nowadays all fragments are exposed on the walls of naves. Regarding the marbles of the ciborium, in 2012 the existing fragments were relocated to panels, with standard dimensions of $207 \mathrm{~cm}$. x $110 \mathrm{~cm}$. $\times 9 \mathrm{~cm}$., that are nowadays located in the left wall of the central nave. It is possible to individuate different fragments belonging to four arcades with different ornamental content as listed in Table 1.

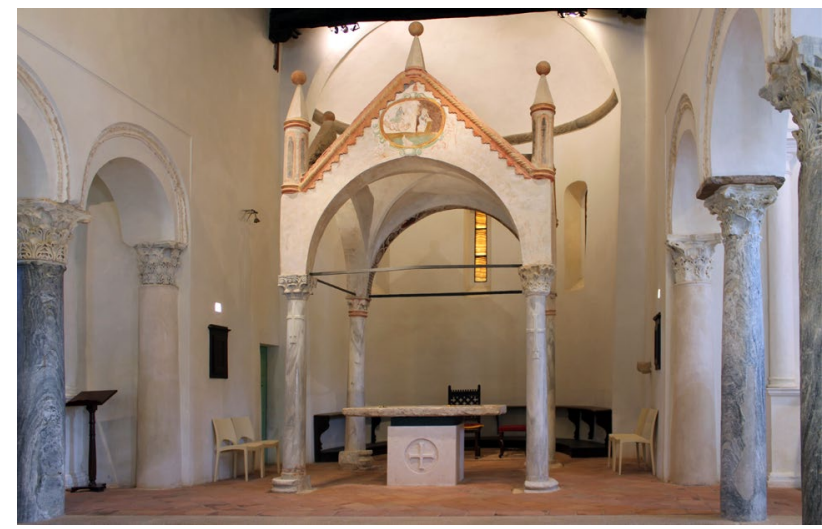

Figure 1. Current ciborium of Monte Sorbo's church

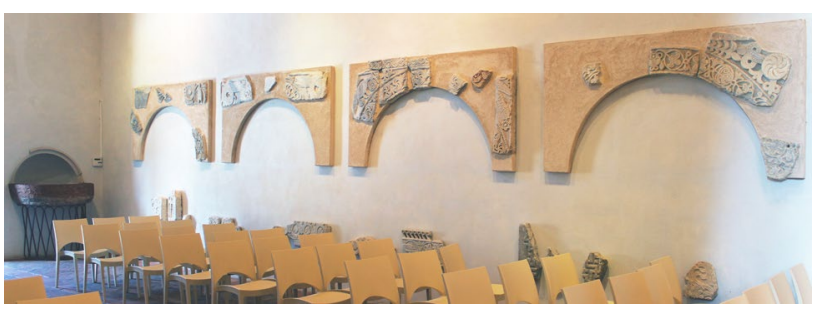

Figure 2. Fragments of sculpted arcades of the original ciborium

\section{METHODOLOGY}

The methodology applied to the case study consists of different phases that involve data and information used in virtual reconstruction processes:

- Collection and acquisition: relevant information was collected to individuate fragments to acquire and to support the threedimensional reconstruction workflow. In particular, was individuated iconographical documentation and previous studies to support the reconstruction process of decorative contents.

- Processing: to process acquired data were used Agisoft Photoscan software which led to the creation of the textured and scaled 3D models.

- Analysis and Interpretation: were created a first geometrical layer to re-compose the fragments, and then a $2 \mathrm{D}$ layer with more detailed decoration.

- 3D modelling and visualisation: starting from the 2D layer developed, a first phase consisted on the $3 \mathrm{D}$ modelling of missing architectural forms using three-dimensional mathematical modelling software (Rhinoceros) and finally, the produced models were prepared to be published to the web using $3 \mathrm{DHOP}$ online presenter.

\subsection{Data collection}

The presence of an ancient ciborium is testified by the presence of fragments of arcades and the hypothesis that also columns belongs to the same complex can be supported by the study of provenance of marbles (Antonelli et al., 2016).

The presbyterium of oratory is elevated by two steps. Therefore, the existence of the pergola which separated the sanctuary area 
and the congregation area is still unknown. However, the presence of numerous fragments of marble slabs and plutei suggests the presence of functional elements to delimit the space of the sacred building (Porta, 2014).

The reference used to hypothesise the design of the Monte Sorbo's pergola is the marble liturgical installation in the monastery dedicated to Saint Panteleimon in Nerezi, Macedonia. Vertical elements of the pergola are usually made by monolithic stone but sometimes slabs are in between by stone pilasters whose lower part is square-shaped and ends with small columns and capitals. Above this main construction, there was a stone or a wooden beam (Jeličić-Radonić, 1999).

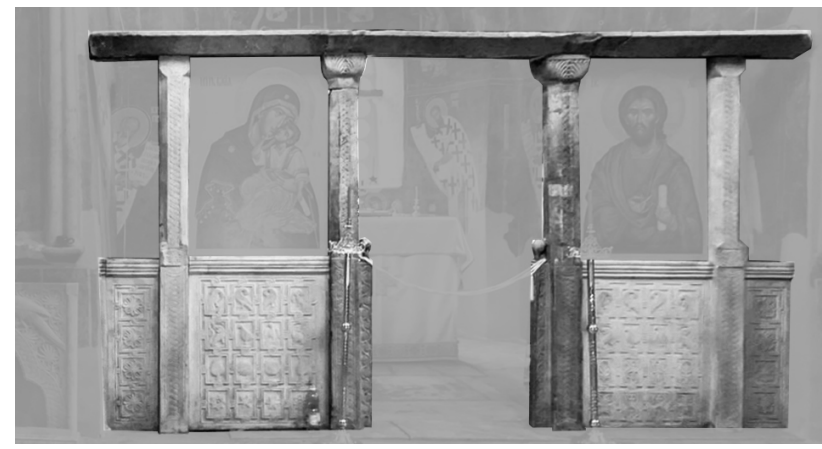

Figure 3. liturgical installation of St. Panteleimon in Nerezi

The hypothesis for Monte Sorbo's pergola considers the presence of a lintel at a height of $2 \mathrm{~m}$. supported by four pillars of different sizes surmounted by squared capitals. These pillars rest in turn on others that interpose marble slabs of different sizes, creating a sort of balustrade or fence.

Three slabs were identified in the lapidarium and were reconstructed in proportions and decorations. As the fourth slab was chosen a pluteus with figures of birds and vine shoots. the pluteus is composed of two fragments, one of which is located in the outer wall of the apse of the church. In this hypothesis, slabs are supported by small pillars, one of which has been identified in the one with dextera Domini inside the lapidarium of the church.

\subsection{Data acquisition}

Today various surveying methods allow the creation of threedimensional models (Adamopoulos and Rinaudo, 2019). To acquire data of architectural elements of ciborium and pergola was used a photogrammetric technique based on structure-frommotion (SfM) approach. This modern technique has been developed since the nineties of the twentieth century and in recent times is the most widely used technology for the digitisation of objects in the field of Cultural Heritage.

The photographic survey campaign took place in two days and was carried out using the Canon EOS 600D digital camera at 18 MP with a Canon EF-S 18-55 IS II mm lens.

During the photo shooting session were acquired four columns with capitals, the twenty marble fragments belonging to the four arcades of ciborium and finally those elements characterizing the pergola system. For each acquired elements, were taken between 6 and 90 images according to the complexity of the elements trying to obtain the smallest number of images to facilitate the processing phase.

The fragments of the arcades and pergola elements (a fragment of the architrave, marble slabs and one pillar) were acquired with a focal length of $35 \mathrm{~mm}$, with exposure set to $1 / 40 \mathrm{sec}$ at $\mathrm{f} / 4.5 \mathrm{ISO}$ 1600. The outside fragment of the pluteus was acquired with a focal length of $55 \mathrm{~mm}$, with exposure set to $1 / 60 \mathrm{sec}$ at $\mathrm{f} / 6.3 \mathrm{ISO}$
200. The columns with capitals were acquired with a focal length of $18 \mathrm{~mm}$, with exposure set to $1 / 50 \mathrm{sec}$ at $\mathrm{f} / 3.5$ ISO 1600 .

For each element was made a shooting session with X-Rite ColorChecker Classic (CC) to avoid the colour difference of textures in the final recomposed 3D model.

For each image dataset was made the colour correction with white balance using the patch 22 of the $\mathrm{CC}$.

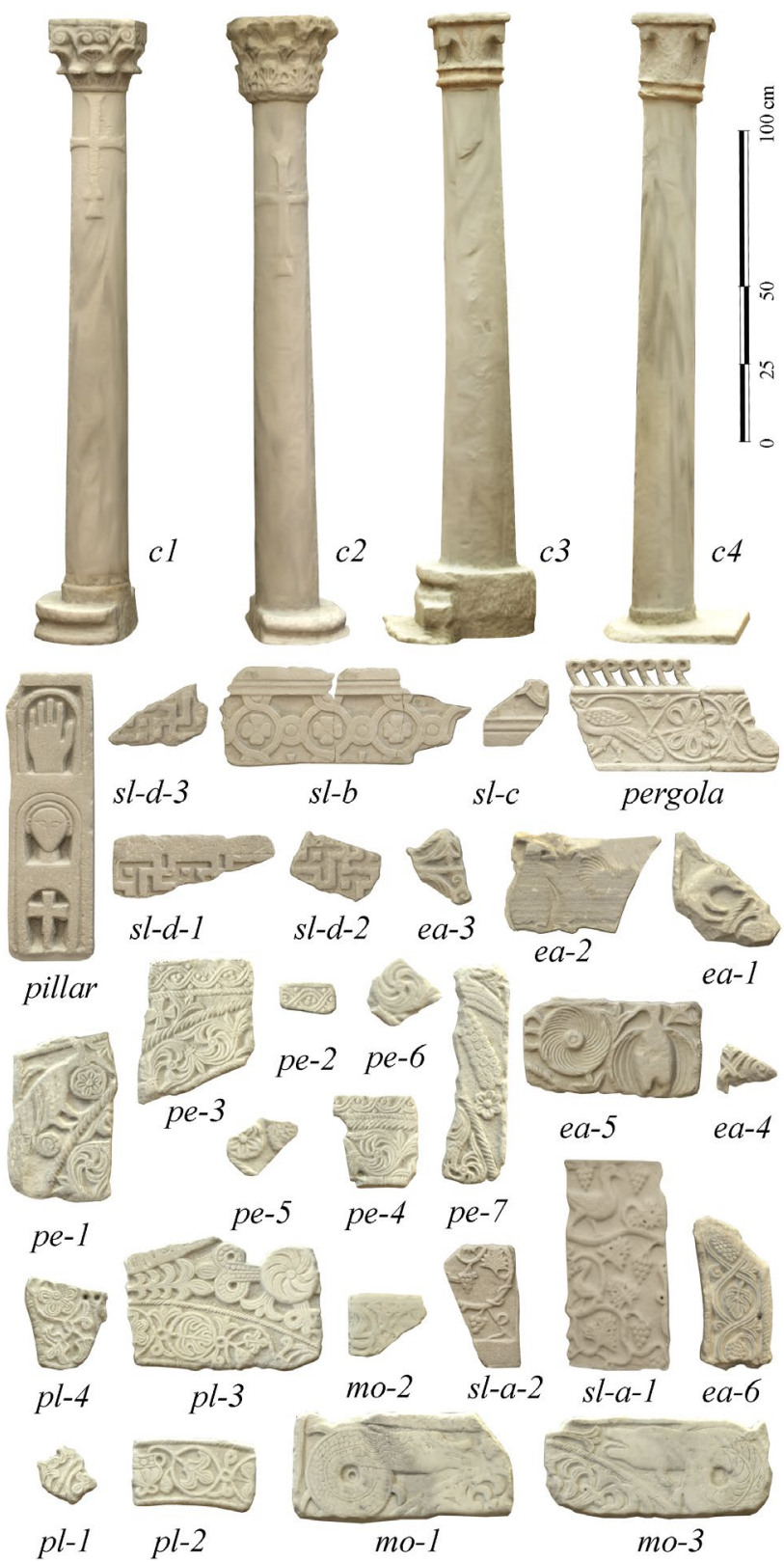

Figure 4. Abacus of acquired elements and their encoding

\subsection{Data Processing}

The data processing of elements was made using Agisoft Photoscan. All elements of the ciborium and pergola were scaled using Scale Bars.

In the case of arcades of the ciborium, the measures of the existing panel $(207 \mathrm{~cm}$. x $110 \mathrm{~cm}$. x $9 \mathrm{~cm}$.) were used as a reference to set up the distance values. The image dataset for fragments of arcades was aligned in a single chunk to generate point cloud and dense cloud. Then the chunk was duplicate to generate $3 \mathrm{~d}$ models with textures for each acquired element. 
After this phase, the developed 3D models were managed using Rhinoceros to recomposing elements according to geometrical rules derived from the analysis of their decorations and motifs. The early medieval ciborium digitally reconstructed was then inserted in the apse of the church according to its ancient hypothetical location, behind the pergola.

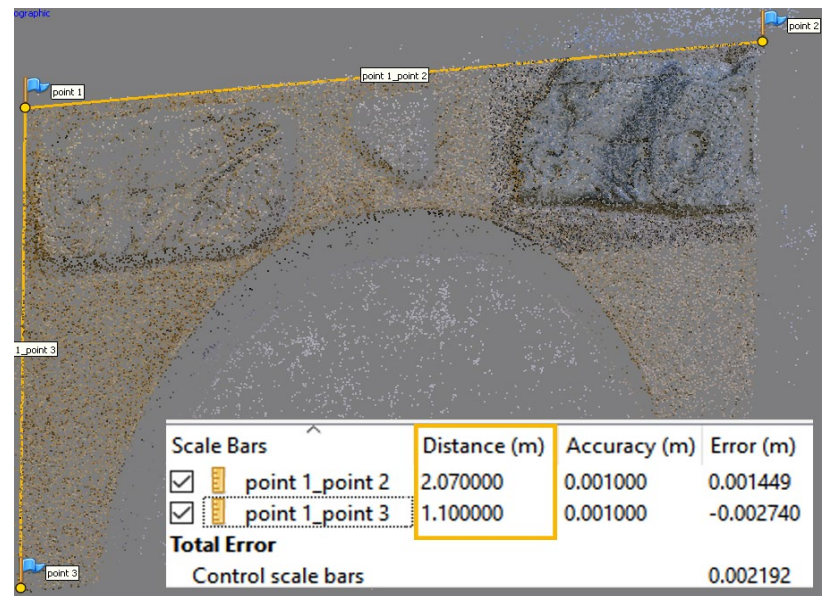

Figure 5. Scaling acquired panels using a known distance

\subsection{Data analysis and interpretation: the ciborium}

According to the ICOMOS Charter for the Interpretation and Presentation of Cultural Heritage Sites (2007), "visual reconstructions [...] should be based upon detailed and systematic analysis of environmental, archaeological, architectural, and historical data, including analysis of written, oral and iconographic sources, and photography. The information sources on which such visual renderings are based should be clearly documented and alternative reconstructions based on the same evidence, when available, should be provided for comparison". The digital integration of missing decorative elements of the arcades of the ciborium was based on the analysis of decoration in 2D followed by a digital drawing of missing decorative elements and finally digitally modelled using a $3 \mathrm{D}$ software.

The arcades of the ciborium (mo, ea, pl, pe) show the typical tripartite decorative scheme with different registers: a frame on the top, the archivolt and two spandrels, the triangular-shaped ornamental areas (with different decorative elements) between the extrados of the arch and the rectangular framework surrounding it. The first step was to identify the perimeter of the arcades and the radius of the circumference of their arches, positioning and rotating fragment. A second alignment was made analysing the decorations and derived geometrical rules.

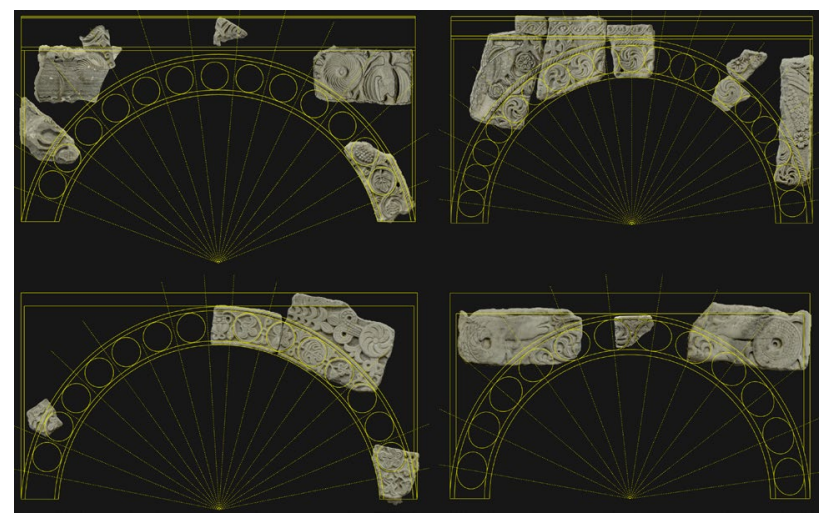

Figure 6. Geometrical rules in the arcades of the ciborium
This analysis, aimed at the virtual recomposition of fragments showed how all arcades have a height of $1.15 \mathrm{~m}$. and a two by two widths of $2.07 \mathrm{~m}$. and $2.27 \mathrm{~m}$. This confirms the hypothesis of Porta which presupposed slabs with uniform measurements two by two (Porta, 2014). The conclusion of the geometrical analysis differs from the Porta hypothesis that assumed as the wider slabs, the arcades with a decoration of peacocks and plant motifs. The digital replica of decorations suggests that the wider arcades are the ones with the decoration of eagles (positioned in the front one) and the arcade with a decoration of plant motifs (positioned at the back). The narrower arcades were digitally placed at the sides: the one with a decoration of peacocks positioned on the left and the opposite one with a decoration of marine monsters (Giovannini, 2014).

The arrangement of the marble columns and the order of the capitals has remained unchanged according to the current scheme. The columns with a cross ( 1 and $\mathrm{c} 2)$ remain on the main front, while the others ( $\mathrm{c} 3$ and $\mathrm{c} 4$ ) on the back.

The pyramid roof of the ciborium is deducted by a typological comparison and was probably shaped like a cusp (Porta, 2014).

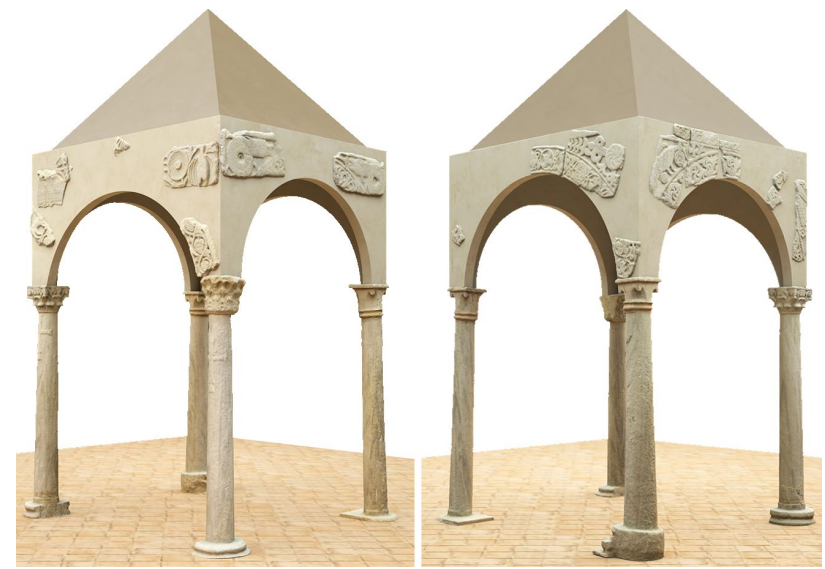

Figure 7. 3D model of the ciborium - view of the four arcades

To scientifically validate the virtual reconstruction, this project started identifying reference sources gathered and classifying them using the linear scale proposed by Apollonio (2016).

This scale can be considered as a classification scheme for visualisation of uncertainty and its colours can be used to label 3D elements in the reconstruction. In the case of the ciborium and pergola, the sources available correspond to colours n. 1 (acquired fragments and columns), 6 (integration of missing decorative elements based on a specific architectural style) and 7 (pyramid roof of the ciborium).

1. r.c. based on archaeological/architectural evidence

2. r.c. based on original drawings

3. r.c. based on design data related to stylistic similarities

4. r.c. on treaties, books, etc. written by the author

5. r.c. based on reference to treaties books, journals, etc.

6. r.c. based on reference to a specific architectural style and/or historical period

7. r.c. based on reference to coeval building systems

8 reconstructive conjectures failing references

Figure 8. Uncertainty gradient colour code (Apollonio, 2016)

The uncertainty of a source differs from the accuracy of the information and explicit or implicit knowledge that can be derived from it. For example, sometimes it is possible to have archaeological or architectural evidence that is not conserved enough well to be useful in the geometric reconstruction of the 



Figure 8. Uncertainty scale for reconstruction applied to 2D decorative elements of arcades; fragments integrated with decorations

artefact. In this case, it is possible to talk about different levels of information that can be used in the reconstruction processes.

The uncertainty gradient colour code can be applied to sources and can be considered a level of information for reference sources.

The granularity of required information to document interpretative processes, in this case, cannot stop at the reference level but need to go deeper to explain how the reference sources were interpreted. Because the 2D drawings followed the information derived from the analysis of acquired fragments. In this project was introduced a new level of information to clarify the difference between interpretative processes based on diverse sources and previous studies.

The information extrapolated by the sources can be of three types:
- indicated: when the information is explicitly derived from the reference source

- deducted: when the information is the result of an interpretation based on implicit assumptions derived from the indicated information

- interpreted: when the information is an interpretation of the reference source

The result is a matrix that can generate 24 diverse interpretative processes that can be documented using visualisation tools. As shown in the following figures the colour of lines for 2D drawings follows the colour assigned at the reference source with a difference in the type of lines. For indicated and interpreted information, the lines are continuous. For deducted elements lines are dashed. 


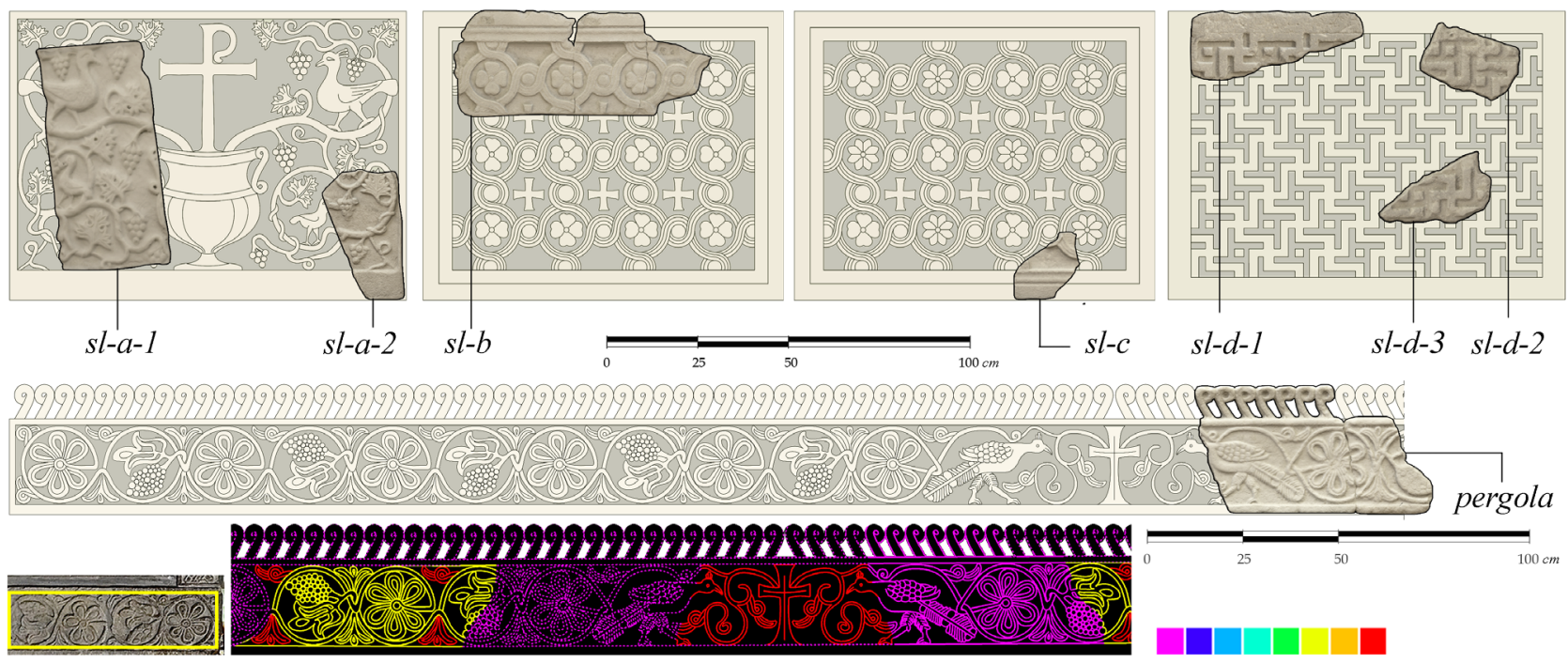

Figure 9. Uncertainty scale for reconstruction applied to 2D decorative elements of pergola; fragments integrated with decorations

The Arcade with a decoration of peacocks was the easiest to recompose because all elements of the decorative scheme were available and clear. In the top frame, the main decorative motif is repeated 24 times in length. The $2 \mathrm{D}$ integrations were deducted from fragments pe-2/3/4. The archivolt has an arch with a span of $1.64 \mathrm{~m}$. and an arrow of $82 \mathrm{~cm}$. with a decoration that generates a sequence of 19 elements deducted from pe-1/3/4/6/7. The most complex decoration to reproduce is the decorative elements of spandrels: in this case figures of peacocks. According to specific architectural style, the decorations were usually similar and mirrored according to an axis of central symmetry. Other elements surrounding the peacocks have been deduced from the respective fragments pe-1/5/7 on right or left spandrel and their motifs were easily deducted because based on recognizable geometries.

The Arcade with a decoration based on plant motif has a top frame without decoration. Some little lines in fragment pl-3 can suggest the presence of an unreadable epigraph. The archivolt has an arch with a span of $1.84 \mathrm{~m}$. and an arrow of $86 \mathrm{~cm}$. with a decoration that generates a sequence of 17 elements. The decorative sequence of each circular element is deducted from all fragments available, pl-1/2/3/4. Also in this case elements indicated were mirrored to generates deducted decoration motifs according to an axis of central symmetry. The decorative elements in spandrels are based on a plant motif depicted in fragment pl-3. The other elements were added following the incomplete traces but with failing references for decorative reproduction. Hypothesizing them as build on a geometrical basis and in congruence with the horror vacui that characterizes the style of all four arches.

The Arcade with a decoration of marine monsters has a top frame without decoration. The archivolt has an arch with a span of $1.61 \mathrm{~m}$. and an arrow of $81 \mathrm{~cm}$. Its decoration is based on fragments mo- $1 / 2 / 3$ and the motif generates a sequence of 17 elements that are based on oval and not circular elements as in the other archivolts. The decorative elements in spandrels are based on fragments mo-1/3 and depict figures of marine monsters. In both fragments, the terminal part of the animals is missing. In this case, the integration was interpreted based on decorative similarities recognizable in the marine monsters of the ambo in the Cathedral of Ravello (Salerno).

The Arcade with a decoration of figures of eagles was the most complex one. The archivolt has an arch with a span of $1.83 \mathrm{~m}$. and an arrow of $71 \mathrm{~cm}$. Its form is based on the geometrical alignment of fragments ea- $1 / 5 / 6$ but the decoration, that generates a sequence of 15 elements, is deducted only by fragments ea- $1 / 6$. The top frame has as references the fragments ea- $3 / 4$ and in this case, its decoration is interpreted based on the fragment ea- 3 that has decorative similarities with fragment ea- 6 and suggests an interpretation of the decorative schema of the archivolt. The decorative elements in spandrels, depicting figures of eagles, are based on fragments ea-1/2/3/5. The phytomorphic elements missing from the two lateral triangles were obtained by mirroring the opposite decorations, as in previous arcades. The fragments ea- $1 / 2$ depict a four-legged figure, probably a sheep, as the prey of an eagle. Other invention elements were inserted to close the remaining spaces taking up the motif of the cross enclosed between opposing flowers already present in the ciborium's arcade with figures of peacocks.

\subsection{Data analysis and interpretation: the pergola}

The fragment pergola belongs to the architrave of the pergola. According to the hypothetical position of the liturgical installation inside the church and to the symmetrical decoration of 11 elements, it was deducted that the architrave should have a length of $5.78 \mathrm{~m}$. Its decoration depicts a peacock figure facing left followed by plant motifs inside interweaved circles that have stylistic similarities with a balustrade pillar inside the parish church of Trebbio (Modena).

The pergola in this hypothetical reconstruction was composed of four slabs. The most difficult to reinterpreted was pluteus. The geometrical recomposition was based on fragments sl-a- $1 / 2$ following and integrating a precedent study that proposed an iconographic reconstruction of the original relief choosing a solution similar to the one of Sant'Apollinare Nuovo in Ravenna (Rizzardi, 1979).

The other sabs were more intuitive to redraw because the available fragments allowed to find their geometrical patterns.

The fragments sl-d-1/2/3 were used to recompose a slab with the "swastika pattern". Considering the same dimensions of the pluteus were first individuated the presence of a frame of $6 \mathrm{~cm}$. The geometrical decoration was inscribed inside a smaller rectangular frame with a width of $97.4 \mathrm{~cm}$. and height $67.4 \mathrm{~cm}$. Similar fragments sl-b and sl-c were used to hypothesize the presence of other two slabs that differs only in decoration motifs. The two slabs have a width of $100 \mathrm{~cm}$. and height $80 \mathrm{~cm}$. The dimension of the external frame, derived from the geometrical rules of decoration that is inscribed inside a smaller rectangle with a width of $83.8 \mathrm{~cm}$. and height $63.4 \mathrm{~cm}$. In both slabs, the 
proposed geometric rule doesn't change: flowers inscribed in the circles and small crosses in the resulting spaces. The difference between them is in the sequence and type of flowers.

\section{3D MODELLING AND VISUALISATION}

After the analysis and reinterpretation of geometrical rules for decoration of elements of the ciborium and pergula, were created three-dimensional solid elements to support the virtual recomposition of fragments. These solids allow visualising the entire liturgical installation showing how it is incomplete and fragmentary.

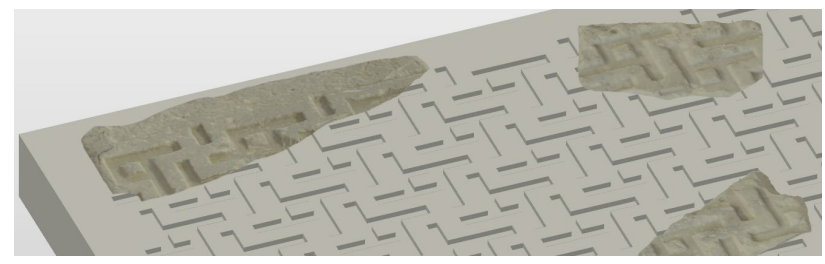

Figure 10. 3D modelling integration

Starting from the generic solids, a second phase was the production of $3 \mathrm{D}$ models for the integration of missing elements. In this phase, the decoration produced in the phase of analysis was simplified, when necessary, changing its level of detail. The new 2D layer was used to model elements using first the extrude command and then fillet command inside Rhinoceros software.

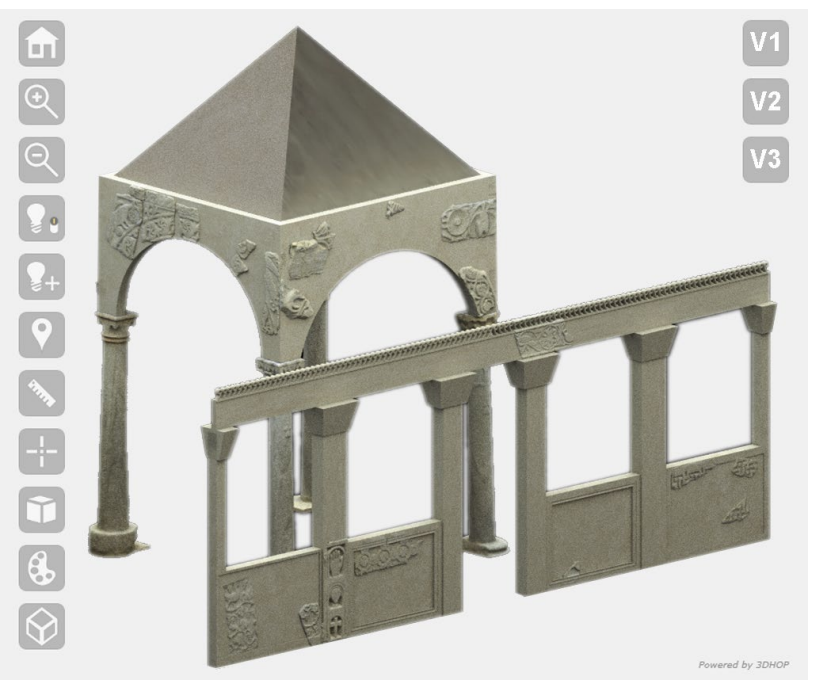

Figure 11. 3D model published with 3DHOP

Finally, the 3D models were uploaded to the web using the 3D Heritage Online Presenter (3DHOP). As already mentioned in the introduction, 3DHOP was designed to support and interconnect different models changing their visualisation. Thanks to the visibility options available within the framework, were individuated 3 types of visualisation with three different types of information:

V1) 3D model with textured fragments recomposed and solid elements with a monochrome texture

V2) 3D model with textured fragments recomposed and solid elements textured using images from the 2D layer of decoration V3) 3D model with textured fragments recomposed and integrated 3D elements

Model instances in 3DHOP can be configured to be visible or invisible. To change their visibility can be using specific JavaScript functions that can be activated by buttons in the webpage. A diverse visualisation was assigned to each button $\mathrm{V} 1, \mathrm{~V} 2$ and V3 in the right side of the webpage. To all instances were assigned a specific tag which has a property that affects its visibility, according to the three solutions.

\section{CONCLUSIONS}

The workflow shows how new technologies can facilitate the comprehension of cultural heritage allowing to produce content for a scientific audience and a large public.

The proposed solution, documents conjectures related to the virtual reconstruction process adding to the uncertainty gradient colour scale used to classify sources, a secondary level of information related to the cognitive process involved into the development of hypothetical reconstruction of decorative elements. This approach provides a useful flexible solution to document interpretative processes that require to be extensively documented.

The web-based framework used to visualise 3D models can support the narrative in a new and attractive way respecting the principles of transparency of virtual reconstruction processes. The fruition of content through three levels of information allows to understand the research and its modelling phases in a comprehensive way.

These tools are changing the way to communicate results and will help the cultural heritage and academia community to create and share advanced contents for all.

\section{REFERENCES}

Abate, D., Furini, G., Migliori, S., Pierattini, S., 2011. Ricomposizione virtuale del tabernacolo di Isaia da Pisa per la chiesa della ss. trinità di Viterbo. Archeomatica 2, 30-34

Abati, M., Camporesi, P., 2014. Storia della Pieve e del Pievato, in: Mengozzi, M. (Ed.), La Pieve Di Monte Sorbo. Editrice Stilgraf, Cesena, Italy, 77-108.

Adamopoulos, E., Rinaudo, F., 2019. An updated comparison on contemporary approaches for digitization of heritage objects. 2019 IMEKO TC4 Int. Conf. Metrol. Archaeol. Cult. Heritage, MetroArchaeo 2019 1-6.

Adembri, B., Cipriani, L., Bertacchi, G., 2017. Guidelines for a digital reinterpretation of architectural restoration work: Realitybased models and reverse modelling techniques applied to the architectural decoration of the teatro marittimo, villa adriana. Int. Arch. Photogramm. Remote Sens. Spat. Inf. Sci. - ISPRS Arch. 42, 599-606.

Antonelli, F., Santi, P., Renzulli, A., Santoro Bianchi, S., 2016. The Architectural Reuse of Roman Marble and Stone Spolia in the Early Medieval Monte Sorbo Church (Sarsina, Central Italy). Archaeometry 58, 353-370.

Apollonio, F.I., 2016. Classification Schemes for Visualization of Uncertainty in Digital Hypothetical Reconstruction, in: $3 D$ Research Challenges in Cultural Heritage II. 173-197.

Apollonio, F.I., Gaiani, M., Sun, Z., 2013. 3D Modeling and Data Enrichment in Digital Reconstruction of Architectural Heritage. XXIV Int. CIPA Symp. Arch. Photogramm. Remote Sens. Spat. Inf. Sci. XL-5/W2, 43-48.

Apollonio, F.I., Giovannini, E.C., 2015. A Paradata Documentation Methodology for the Uncertainty Visualization in Digital Reconstruction of Ch Artifacts. Scires-It-Scientific Res. Inf. Technol. 5, 1-24. 
Behr, J., Eschler, P., Jung, Y., Zöllner, M., 2009. X3DOM - A DOM-based HTML5/ X3D integration model. Proc. Web3D 2009 14th Int. Conf. Web3D Technol. 1, 127-135.

Borghini, S., Carlani, R., 2011. La restituzione virtuale dell'architettura antica come strumento di ricerca e comunicazione dei beni culturali: ricerca estetica e gestione delle fonti. DISEGNARECON 4, 71-79.

Boutsi, A.M., Ioannidis, C., Soile, S., 2019. An integrated approach to $3 \mathrm{D}$ web visualization of cultural heritage heterogeneous datasets. Remote Sens. 11, 1-26.

Canciani, M., Falcolini, C., Buonfiglio, M., Pergola, S., Saccone, M., Mammì, B., Romito, G., 2014. Virtual Anastylosis of the Arch of Titus at Circus Maximus in Rome. Int. J. Herit. Digit. Era 3, 393-411.

de Kramer, M., 2020. Relict-Interpolated-ExtrapolatedSpeculative: An Approach to Degrees of Accuracy in Virtual Heritage Reconstruction. Springer International Publishing. https://doi.org/10.1007/978-3-030-37191-3_21

Dell'Unto, N., Leander, A.M., Dellepiane, M., Callieri, M., Ferdani, D., Lindgren, S., 2013. Digital reconstruction and visualization in archaeology: Case-study drawn from the work of the Swedish Pompeii Project. Proc. Digit. 2013 - Fed. 19th Int'1 VSMM, 10th Eurographics GCH, 2nd UNESCO Mem. World Conf. Plus Spec. Sess. from CAA, Arqueol. 2.0 al. 1, 621-628.

Demetrescu, E., Ferdani, D., Dell'Unto, N., Touati, A.-M.L., Lindgren, S., 2016. Reconstructing the original splendour of the House of Caecilius Iucundus. A complete methodology for virtual archaeology aimed at digital exhibition. SCIRES-IT -Sci. Res. Inf. Technol. 6, 51-66.

Denard, H., 2012. An Introduction to the London Charter, in: Bentkowska-kafel, A., Denard, H., Baker, D. (Eds.), Paradata and Transparency in Virtual Heritage. ASHGATE, pp. 57-78.

Friedrichs, K., 2018. 3D Reconstruction Techniques as a Cultural Shift in Art History? International Journal for Digital Art History 3. https://doi.org/10.11588/dah.2018.3.32473

Giovannini, E.C., 2014. Un'ipotesi di ricomposizione virtuale, in: Marino Mengozzi (Ed.), La Pieve Di Monte Sorbo. Stilgraf, CESENA - ITA, 355-386.

Guidi, G., Frischer, B., Lucenti, I., 2007. Rome Reborn Virtualizing The Ancient Imperial Rome. Arch. Photogramm. Remote Sens. Spat. Inf. Sci. XXXVI-5/W4, 1-4.

Hermon, S., 2008. Reasoning in 3D: A critical appraisal of the role of 3D modelling and virtual reconstructions in archaeology., in: Frischer, B. (Ed.), Beyond Illustration: 2D and 3D Digital Technologies as Tools for Discovery in Archaeology. Tempus Reparatum, Oxford, 36-45.

Jeličić-Radonić, J., 1999. Liturgical Installations in the Roman Province of Dalmatia. Hortus Artium Mediev. 5, 133-145.

Kuroczynski, P., 2017. Virtual Research Environment for digital 3D reconstructions - Standards, thresholds and prospects. Stud. Digit. Herit. 1, 456-476.

London Charter. For the Computer-Based Visualisation of Cultural Heritage. www.londoncharter.org (last accessed on May 2020)
Martinez-rubi, O., Verhoeven, S., Meersbergen, M. Van, Schuetz, M., van Oosterom, P., Gonclves, R., Tijssen, T., 2015. Taming the beast: Free and open-source massive point cloud web visualization. Capturing Real. Forum 2015, 23-25.

Mengozzi, M., 2014. Una pieve-reliquia, in: Mengozzi, M. (Ed.), La Pieve Di Monte Sorbo. Editrice Stlgraf, 8-22.

Mi, X., Pollock, B.M., 2018. Metadata Schema to Facilitate Linked Data for 3D Digital Models of Cultural Heritage Collections: A University of South Florida Libraries Case Study. Cat. Classif. Q. 56, 273-286.

Moraitou, E., Aliprantis, J., Christodoulou, Y., Teneketzis, A., Caridakis, G., 2019. Semantic Bridging of Cultural Heritage Disciplines and Tasks. Heritage 2, 611-630.

Münster, S., 2013. Workflows and the role of images for virtual $3 \mathrm{D}$ reconstruction of no longer extant historic objects. ISPRS Ann. Photogramm. Remote Sens. Spat. Inf. Sci. 1-5/W1, 197-202.

Münster, S., Apollonio, F. I., Bell, P., Kuroczynski, P., Di Lenardo, I., Rinaudo, F., Tamborrino, R., 2018. Digital humanities meet digital cultural heritage. Arch. Photogramm. Remote Sens. Spat. Inf. Sci., XLII-2/W15, 813-820

Niccolucci, F., Hermon, S., 2010. A fuzzy logic approach to typology in archaeological research. Beyond Artifact. Digit. Interpret. Past. Proc. CAA2004, Prato 13-17 April 2004, 28-35.

Porta, P., 2014. L'arredo scultoreo, in: Mengozzi, M. (Ed.), La Pieve Di Monte Sorbo. Editrice Stilgraf, 161-284.

Potenziani, M., Callieri, M., Dellepiane, M., Corsini, M., Ponchio, F., Scopigno, R., 2015. 3DHOP: 3D Heritage Online Presenter. Comput. Graph. 52, 129-141.

Potenziani, M., Callieri, M., Scopigno, R., 2018. Developing and Maintaining a Web 3D Viewer for the $\mathrm{CH}$ Community: an Evaluation of the 3DHOP Framework. 16th Work. Graph. Cult. Herit. Eurographics Int. Conf. (Proc. Of).

https://doi.org/10.2312/gch.20181356

Reilly, P., 1991. Towards a virtual archaeology. CAA90. Comput. Appl. Quant. Methods Archaeol. 1990 (BAR Int. Ser. 565) 132 139.

Remondino, F., El-hakim, S., Girardi, S., Rizzi, A., Benedetti, S., Gonzo, L., 2009. 3D Virtual Reconstruction and Visualization of Complex Architectures - The 3D-ARCH Project. Int. Arch. Photogramm. Remote Sens. Spat. Inf. Sci. XXXVIII-5/W1

Rizzardi, C., 1979. Frammento inedito della Pieve di monte Sorbo (Forli). Felix Ravenna CXVII, 33-56.

Sevilla Charter. International Principles of Virtual Archaeology. $\mathrm{http} / / /$ smartheritage.com/seville-principles/seville-principles (last accessed on May 2020)

Thuswaldner, B., Flory, S., Kalasek, R., Hoffer, M., 2009. Digital anastylosis of the Octagon in Ephesos. J. Comput. Cult. Herit. $2,1,1-27$.

Von Schwerin, J., Richards-Rissetto, H., Remondino, F., Agugiaro, G., Girardi, G., 2013. The mayaarch3d project: A 3D webgis for analyzing ancient architecture and landscapes. Lit. Linguist. Comput. 28, 736-753. 